\section{Distribuição etária do sarampo e vacinação: considerações sobre alguns dados do municipio do Rio de Janeiro}

\author{
Paulo C.R. Barata* \\ Maria do Carmo Leal*
}

* Escola Nacional de Saúde Pública - FIOCRUZ Rio de Janeiro

Some data are presented on the age distribution of the reported cases of measles in the Municipio do Rio de Janeiro, Brazil, between 1964 and 1982, focusing on changes in this distribution between the prevaccination and postvaccination years. These data are compared with those of some other countries and a short discussion is made about the influence of vaccination on the epidemiology of measles.

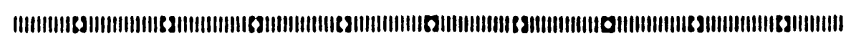

\section{INTRODUÇÃO}

Neste trabalho apresentaremos alguns dados sobre a distribuição etária dos casos notificados de sarampo no Município do Rio de Janeiro entre 1964 e 1982, procurando ressaltar a modificação ocorrida nesta distribuição etária desde a introdução da vacinação anti-sarampo no município. Várias observações a este respeito têm sido feitas em diversos países, algumas das quais serão apresentadas no decorrer da discussão, procurando chamar a atenção do leitor para uma questão que parece se repetir em diversos lugares. A discussão compreenderá, ainda, uma breve revisão sobre os possíveis mecanismos e efeitos desta relação entre a vacinação, a distribuição etária e, de forma geral, a epidemiologia do sarampo, questões que têm sido já objeto de diversos estu$\operatorname{dos}^{1,2,12}$ e que deveriam ser consideradas no planejamento e análise de programas de imunização.

\section{MÉTODOS}

Os dados referentes ao número de casos para o período 1964-1974 foram fornecidos pela Divisão de Fatos Vitais do Departamento de Análise de Dados da Secretaria de Estado de Saúde e Higiene do Rio de Janeiro, e os dados para o período 1975-1982, assim como o número de doses de vacina anti-sarampo aplicadas em menores de 1 ano foram fornecidos pela Divisão de Epidemiologia e Controle de Doenças da Secretaria Municipal de Saúde do Rio de Janeiro.

A cobertura vacinal em menores de 1 ano foi calculada estimando-se a população de menores de 1 ano pelo mé- 
todo geométrico ${ }^{15}$, a partir das populações de 1970 e 1980 publicadas pelos Censos Demográficos do $\mathrm{IBGE}^{4}, 5$.

\section{RESULTADOS}

Os Dados do Município do Rio de Janeiro

As tabelas 1 e 2 apresentam a distribuição etária dos casos notificados de sarampo no Município do Rio de Janeiro (população: 5.090.723 habitantes em 19805) em diversos períodos de tempo. Observa-se que, enquanto os períodos 1964-1967 e 1969-1972 têm uma distribuição bastante aproximada, a partir de 1973 a distribuição etária dos casos notificados vai sofrendo uma nítida modificação, com uma tendência a um aumento na idade média em que ocorrem os casos da doença.

\section{TABELA 1}

Casos notificados de Sarampo (média anual) por grupo etério, munictpio do Rio de Janeiro, 1964-1967, 1969.1972, 1975.1978 e 1979.1982.

\begin{tabular}{|c|c|c|c|c|c|c|c|c|}
\hline \multirow{2}{*}{$\begin{array}{l}\text { Grupo etário } \\
\text { (anos) }\end{array}$} & \multicolumn{2}{|c|}{$1964-1967$} & \multicolumn{2}{|c|}{$\underline{1969-1972}$} & \multicolumn{2}{|c|}{$\underline{1975-1978}$} & \multicolumn{2}{|c|}{$\underline{1979-1982}$} \\
\hline & No & $\%$ & No & $\%$ & № & $\%$ & No & $\%$ \\
\hline $\begin{array}{r}<1 \\
1-4 \\
5 \mathrm{e}+\end{array}$ & $\begin{array}{l}135 \\
593 \\
275\end{array}$ & $\begin{array}{l}13.5 \\
59.1 \\
27.4\end{array}$ & $\begin{array}{l}281 \\
932 \\
414\end{array}$ & $\begin{array}{l}17.3 \\
57.3 \\
25.4\end{array}$ & $\begin{array}{l}201 \\
573 \\
438\end{array}$ & $\begin{array}{l}16.6 \\
47.3 \\
36.1\end{array}$ & $\begin{array}{l}268 \\
846 \\
964\end{array}$ & $\begin{array}{l}12.9 \\
40.7 \\
46.4\end{array}$ \\
\hline $\begin{array}{l}\text { Total de casos com } \\
\text { idade conhecida }\end{array}$ & 1003 & 100.0 & 1627 & 100.0 & 1212 & 100.0 & 2078 & 100.0 \\
\hline $\begin{array}{l}\text { Idade Ignorada } \\
\text { Total notificado }\end{array}$ & $\begin{array}{r}11 \\
1014\end{array}$ & & $\begin{array}{r}25 \\
1652\end{array}$ & & $\begin{array}{r}43 \\
1255\end{array}$ & & $\begin{array}{r}87 \\
2165\end{array}$ & \\
\hline
\end{tabular}

TABELA 2

Casos notificados de Sarampo (média anual) por grupo etário, munictpio do Rio de Janeiro, $1969.1972,1973.1974,1975.1978$ e 1979.1982 .

\begin{tabular}{|c|c|c|c|c|c|c|c|c|}
\hline \multirow{2}{*}{$\begin{array}{l}\text { Grupo etário } \\
\text { (anos) }\end{array}$} & \multicolumn{2}{|c|}{$1969-1972$} & \multicolumn{2}{|c|}{$1973-1974$} & \multicolumn{2}{|c|}{$1975-1978$} & \multicolumn{2}{|c|}{$1979-1982$} \\
\hline & Nọ & $\%$ & Nọ & $\%$ & No & $\%$ & Nọ & $\%$ \\
\hline$<1$ & 281 & 17.3 & 231 & 16.3 & 201 & 16.6 & 268 & 12.9 \\
\hline $1-4$ & 932 & 57.3 & 789 & 55.5 & 573 & 47.2 . & 846 & 40.7 \\
\hline $5-14$ & 372 & 22.9 & 346 & 24.3 & 320 & 26.4 & 746 & 35.9 \\
\hline $15 e+$ & 42 & 2.6 & 55 & 3.9 & 119 & 9.8 & 218 & 10.5 \\
\hline $\begin{array}{l}\text { Total de casos com } \\
\text { idade conhecida }\end{array}$ & 1627 & 100.0 & 1421 & 100.0 & 1213 & 100.0 & 2078 & 100.0 \\
\hline Idade Ignorada & 25 & & 6 & & 43 & & 87 & \\
\hline Total notificado & 1652 & & 1427 & & 1256 & & 2165 & \\
\hline
\end{tabular}

Segundo informações (não publicadas) colhidas junto à Divisão de Epidemiologia e Controle de Doenças da Secretaria Municipal de Saúde do Rio de Janeiro, a vacinação antisarampo no município começou, de forma experimental, 
em 1968, passando a ser realizada de forma regular apenas a partir de 1973. A tabela 3 mostra a cobertura vacinal estimada para os menores de 1 ano entre 1970 e 1982 (não se dispõe de dados sobre vacinação em menores de 1 ano para 1968 e 1969). Pode-se observar que esta cobertura vacinal apresenta uma tendência crescente neste período, passando de 18,8\% em 1973 para 76,8\% em 1982.

\section{TABELA 3}

Doses de vacina anti-Sarampo aplicadas em menores de 1 ano e cobertura vacinal estimada para os menores de 1 ano, munictpio do Rio de Janeiro, 1970-1982.

\begin{tabular}{lcc}
\hline Ano & $\begin{array}{c}\text { No de Doses } \\
\text { Aplicadas }\end{array}$ & $\begin{array}{r}\text { Cobertura } \\
\text { Vacinal (\%) }\end{array}$ \\
\hline 1970 & 6256 & 7.8 \\
1971 & 4792 & 5.8 \\
1972 & 12333 & 14.6 \\
1973 & 16208 & 18.8 \\
1974 & 30968 & 34.9 \\
1975 & 9382 & 10.3 \\
1976 & 23370 & 25.0 \\
1977 & 36632 & 38.2 \\
1978 & 40599 & 41.3 \\
1979 & 47500 & 47.1 \\
1980 & 63962 & 61.8 \\
1981 & 79714 & 75.0 \\
1982 & 83723 & 76.8 \\
\hline
\end{tabular}

Assim, das tabelas 1.e 2 vemos que, se antes da introdução da vacinação cerca de $25 \%$ dos casos notificados ocorriam em maiores de 5 anos, no período 1979-1982 tínhamos quase $50 \%$ dos casos notificados ocorrendo neste grupo etário. O grupo dos maiores de 15 anos, que representava no período $1969-1972$ 2,6\% dos casos notificados, passou, no período $1979-1982$, a incluir mais de $10 \%$ do total de casos notificados.

\section{DISCUSSÃO}

Existe, é claro, a possibilidade de que esta modificação na distribuição etária dos casos notificados de sarampo no Município do Rio de Janeiro seja o efeito de alguma mudança no sistema de notificação. Por exemplo, uma melhor notificação por parte das escolas contribuiria para um aumento da idade média dos casos notificados. Sabe-se que a notificação de sarampo no município era, e é ainda, bastante deficiente. Com base na igualdade que, na ausência de vacinação, deve aproximadamente haver entre o número médio anual de casos de sarampo e o número médio anual de nascimentos, estimamos que, no Município do Rio de Janeiro, cerca de $2 \%$ a $3 \%$ dos casos de sarampo eram notificados nos anos imediatamente anteriores ao início da vaci- 
nação. No período 1979-1982, quando a vacinação em menores de 1 ano foi em média de cerca de $65 \%$, estimamos que cerca de $6 \%$ dos casos eram notificados. O conhecimento da distribuição etária real dos casos de sarampo que ocorrem no município exigiria a realização de estudos especiais.

No entanto, mudanças na idade em que ocorrem os casos de sarampo têm sido observadas também em outros países onde a vacinação tenha atingido níveis significativos.

Nos Estados Unidos, a vacinação anti-sarampo foi iniciada em $1963^{6}$. Em 1980, 96\% das crianças que entravam pela primeira vez na escola tinham prova de imunidade ao sarampo (atestado de vacinação ou atestado médico de que teve a doença $)^{7}$. No período $1960-1964$, anterior à vacinação, quando a notificação era estimada em cerca de $10 \%{ }^{6}$, em quatro das 52 áreas de notificação do país (New York City, District of Columbia, Illinois e Massachusetts) 37,2\% dos casos notificados ocorreram em menores de 5 anos e $3,4 \%$ ocorreram em maiores de 15 anos $^{8}$. No período 1976-1978, quando a notificação era estimada como sendo virtualmente completa ${ }^{6}$, em 45 áreas de notificação $15,5 \%$ dos casos notificados ocorreram em menores de 5 anos e $23,7 \%$ ocorreram em maiores de 15 anos $^{6}$. Esta mudança na distribuição etária ocorria juntamente com uma queda no número total de casos notificados no país, que passou de cerca de 438.000 no período $1960-1964^{8}$ para cerca de 42.000 no período $1976-1978^{6}$.

$\mathrm{Na}$ Inglaterra, incluindo Gales, o programa nacional de imunização foi iniciado em $1968^{2}$, e a cobertura vacinal manteve-se desde então praticamente estável em cerca de $50 \%$ dos nascidos de cada ano ${ }^{3}$. É estimado que cerca de $60 \%$ dos casos de sarampo eram notificados no período anterior à vacinação, tendo este percentual se mantido no período posterior ao início da vacinação ${ }^{2}$. O número médio anual de casos notificados passou de cerca de 385.000 no período $1965-1968$ para cerca de 124.000 no período $1975-1978^{2}$. A idade média dos casos notificados passou de cerca de 4,5 anos em 1968 para cerca de 5,5 anos no período $1978-198.0^{3}$, tendo havido assim uma reversão na discreta tendência decrescente da idade média dos casos notificados observada entre 1958 e $1968^{2,3}$.

No Simpósio Internacional sobre Imunização contra o Sarampo, realizado em Washington, D.C., U.S.A., em março de 1982*, foram apresentados relatos, com informações mais ou menos completas, sobre a ocorrência de modificações na estrutura etária dos casos notificados de sarampo em outros países, como Canadá, Polônia, Inglaterra, China e Tcheco-Eslováquia.

É claro que estas al terações na distribuição etária dos casos de sarampo estão relacionadas ao fato de se estar vacinando principalmente crianças, o que faz com que diminua o número de suscetíveis e, portanto, o número de casos da
* Rev. Infect. Dis., vol. 5 (3), 1983. 
doença, nos grupos etários cobertos pela vacinação. Em conseqüência, os casos que ocorrem em jovens e adultos passam a representar um percentual maior do total de casos notificados.

No entanto, além da proteção conferida aos indivíduos vacinados, a vacinação produz um outro efeito, qual seja a diminuição do nível de transmissão do vírus do sarampo na comunidade, o que possibilita um certo nível de proteção mesmo àquelas pessoas não vacinadas. Se uma criança não vacinada está cercada, na sua vizinhança, na escola, etc., por outras crianças já imunizadas em relação ao sarampo, a probabilidade de que ela venha a contrair a doença será menor. Este efeito, o chamado efeito de proteção indireta da vacinação, fará com que, em média, uma pessoa não vacinada leve mais tempo até encontrar o agente da doença, o que fará com que ocorra um aumento na idade média em que o sarampo é contraído, aumento que será tanto maior quanto maior for o nível de cobertura vacinal da comunidade. Para uma discussão mais detalhada sobre o efeito de proteção indireta proporcionado pela vacinação, ou sobre a assim chamada imunidade de grupo (herd immunity, em inglês), e suas implicações na epidemiologia e no controle do sarampo, veja as referências ${ }^{1,2,12}$.

Uma outra conseqüência da redução do nível de transmissão do sarampo causada por um programa de vacinação que não chegasse a erradicar a doença seria um acúmulo de pessoas chegando à idade adulta sem terem tido contato, natural ou via vacinação - que, além de tudo, não é $100 \%$ eficaz - com o sarampo, o que abriria mesmo a possibilidade de epidemias de sarampo em adultos. Um outro fator que poderia contribuir para esta possibilidade seria a perda da imunidade induzida pela vacina, questão em relação à qual existe divergência entre diversos autores: enquanto alguns estudos sugerem que a proteção proporcionada pela vacina é duradoura ${ }^{10,19}$, outros trabalhos, com observações de casos de sarampo em pessoas previamente vacinadas com vacina de vírus atenuado, indicam a possibilidade de perda da imunidade induzida pela vacina 11,20 . Surtos de sarampo em adolescentes e adultos, incluindo pessoas previamente vacinadas, têm sido documentados nos Estados Unidos 9 , 20. $\mathrm{Na}$ Inglaterra, um estudo realizado por Fine e Clarkson $^{2}$ encontrou evidências de estar havendo na população uma proporção crescente de adultos suscetíveis ao sarampo.

Estas alterações no padrão etário do sarampo poderiam ter algumas conseqüências de relevância na epidemiologia da doença. Existem evidências, na Inglaterra ${ }^{13}$ e nos Estados Unidos ${ }^{14}$, de um aumento com a idade do risco de encefalite devida ao sarampo. Um aumento da idade média dos casos de sarampo poderia ainda causar um aumento do risco da ocorrência da doença durante a gravidez. Existem 
evidências, nos Estados Unidos ${ }^{18}$, de um aumento da freqüência de prematuridade è de baixo peso ao nascer como um efeito do sarampo durante a gravidez. Um estudo realizado na Groenlândia ${ }^{16}$ encontrou um alto risco de morte fetal e de malformações congênitas em mulheres infectadas com o sarampo no primeiro trimestre de gravidez. Por outro lado, a ocorrência do sarampo durante a gravidez em mulheres ainda suscetíveis à doença - conforme foi discutido anteriormente, um aumento da proporção de adultos suscetíveis seria um possível efeito de um programa de vacinação - resultaria no nascimento de crianças sem a proteção de anticorpos maternos, tendo a possibilidade de contrair o sarampo com muito pouca idade, com os conhecidos riscos que isto acarretaria.

Quanto à possibilidade de prevenção do sarampo pela vacinação de adultos, existem, nos Estados Unidos ${ }^{9}$, indicações de que a vacinação em adultos pode apresentar uma maior incidência de reações, como febre, exantema e outras.

A discussão apresentada sugere que as alterações na composição etária dos casos de sarampo no Município do Rio de Janeiro sejam um fenômeno real, devido possivelmente à introdução da vacinação no município. Um programa de vacinação criteriosamente planejado pode inegavelmente trazer benefícios significativos, com a redução da morbidade e da mortalidade devidas ao sarampo. No entanto, os dados apresentados, do Município do Rio de Janeiro e de outros países, assim como os argumentos teóricos e os diversos estudos mencionados na discussão, indicam que os efeitos da vacinação sobre a epidemiologia desta doença devem ser acompanhados com atenção. No Brasil, em particular, os dados sobre a incidência do sarampo e sobre a incidência de suas complicações são notoriamente precários, existindo a necessidade de melhoria do sistema de notificação e da realização de estudos especiais que permitissem um melhor conhecimento da epidemiologia desta doença. Um país como a Tcheco-Eslováquia realiza anualmente um inquérito sorológico em uma amostra da população entre 0 e 19 anos, como uma forma de avaliar o próprio programa nacional de imunização ${ }^{17}$. Deve-se notar ainda que as características clínico-epidemiológicas do sarampo, inclusive os efeitos da vacinação, podem variar de país para país, de região para região, dependendo de hábitos sociais, situação nutricional da população, etc., o que torna clara a necessidade de estudos locais quanto ao comportamento desta virose.

Finalmente, os dados e a discussão apresentados sugerem que a vacinação, além de atuar sobre o indivíduo, representa uma intervenção sobre um sistema ecológico vírus-homem-ambiente que tem suas próprias leis e seus próprios pontos de equilíbrio. A eficácia desta intervenção irá depen. 
der do conhecimento que se tenha deste sistema e dos dados disponíveis sobre a sua situação a cada momento.

\section{AGRADECIMENTOS}

Agradecemos à Dra. Rosalina Jorge Koifman, Chefe da Divisão de Epidemiologia e Controle de Doenças da Secretaria Municipal de Saúde do Rio de Janeiro, pelos dados colocados a nossa disposição e, especialmente, por todo o apoio que nos deu no estudo deste aspecto da epidemiologia do sarampo. Agradecemos também ao Dr. Luiz Carlos Ferreiro Lait, Chefe da Divisão de Fatos Vitais do Departamento de Análise de Dados da Secretaria de Estado de Saúde e Higiene do Rio de Janeiro, pelos dados fornecidos para este trabalho.

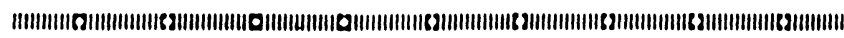

São apresentados alguns dados sobre a distribuição etária dos casos notificados de sarampo no Municipio do Rio de Janeiro entre 1964 e 1982, observando-se a modificação ocorrida nesta distribuição entre o periodo pré-vacinação e o periodo pós-vacinação. Estes dados são comparados com dados de alguns outros paises e é feita uma breve discussão sobre a influência da vacinação na epidemiologia do sarampo.

\section{REFERÊNCIAS BIBLIOGRÁFICAS}

1. BLACK, F.L. The role of herd immunity in control of measles. Yale J. Biol. Med., 55 :351-60, 1982.

2. FINE, P.E.M. \& CLARKSON, J.A. Measles in England and Wales. II. The impact of the measles vaccination programme on the distribution of immunity in the population. Int. J. Epidemiol., 11 :15-25, 1982.

3. FINE, P.E.M. \& CLARKSON, J.A. Measles in England and Wales. III. Assessing published predictions of the impact of vaccination on incidence. Int. J. Epidemiol., $12: 332-9,1983$.

4. FUNDAÇÃO INSTITUTO BRASILEIRO DE GEO. GRAFIA E ESTATÍSTICA. Censo demográfico; Guanabara: 8 ? recenseamento geral do Brasil 1970. Rio de Janeiro, IBGE, 1973. (Série Regional, v. 1, t. 1).

5. FUNDAÇÃO INSTITUTO BRASILEIRO DE GEOGRAFIA E ESTATÍSTICA. Censo demográfico; Rio de Janeiro - dados gerais; migração - instrução, fecundidade, mortalidade: 9 ? recenseamento 
geral do Brasil - 1980. Rio de Janeiro, IBGE, 1983. (v. 1, t. 4, n. 23).

6. HINMAN, A.R. et alii. Current features of measles in the United States: feasibility of measles elimination. Epidemiol. Rev., 2:153-70, 1980.

7. HINMAN, A.R. et alii. Elimination of indigenous measles from the United States. Rev. Infect. Dis., 5: 538-45, 1983.

8. HINMAN, A. R. et alii. Impact of measles in the United States: Rev. Infect. Dis., 5: 439-44, 1983.

9. KRAUSE, P.G. et alii. Epidemic measles in young adults. Ann. Intern. Med., 90: 873-6, 1979.

10. KRUGMAN, S. Present status of measles and rubella immunization in the United States: A medical progress report. J. Pediatr., $90: 1-12,1977$.

11. LNNEMAN, C.C.Jr. et alii. A seroepidemiologic study of a measles epidemic in a highly immunized population. Am. J. Epidemiol., 95 :238-46, 1972.

12. MAY, R.M. Vaccination programmes and herd immunity. Nature, $300: 481-3,1982$.

13. MILLER, D.L. Frequency of complications of measles, 1963. Br. Med. J., 2 :75-8, 1964.

14. ORENSTEIN, W.A. et alii. Current status of measles in the United States, 1973-1977. J. Infect. Dis., 137 :847-53, 1978.

15. RUIZ, F. Conceitos básicos de estatística, demografia e mortalidade. Brasília, Ministério da Saúde, 1976.

16. SAND JESPERSEN, C. et alii. Measles as a cause of fetal defects. A retrospective study of ten measles epidemics in Greenland. Acta Paediatr., Scand., 66: 367-72, 1977.

17. SEJDA, J. Control of measles in Czechoslovakia (CSSR). Rev. Infect. Dis., $5: 564-7,1983$.

18. SIEGEL, M. \& FUERST, H.T. Low birth weight and maternal virus diseases, a prospective study of rubella, measles, mumps, chickenpox and hepatitis. $J A$ MA, 197:88-92, 1966.

19. WEIBEL, R.E. et alii. Follow-up surveillance for antibody in human subjects following live attenuated measles, mumps and rubella virus vaccines. Proc. Soc. Exp. Biol. Med., 162 :328-32, 1979.

20. WEINER, L.B. et alii. A measles ou tbreak among adolescents. J. Pediatr., 90:17-20, 1977. 